\title{
Luiz Beltrão e Gilberto Freyre: reflexões exploratórias acerca da relação entre ciências sociais e comunicação
}

\author{
Luiz Beltrão and Gilberto Freyre: exploratory reflections \\ about the relationship between \\ communication and social sciences
}

\begin{abstract}
Zuleika de Paula Bueno I zubueno@hotmail.com Graduada em Ciências Sociais pela Universidade Estadual de Campinas, Mestre em Sociologia pela Universidade Estadual de Campinas, Doutora em Multimeios pela Universidade Estadual de Campinas e Professora do Departamento de Ciências Sociais e do Programa de Pós-Graduação em

Ciências Sociais da Universidade Estadual de Maringá.
\end{abstract}

Tiago Roberto Ramos I tibobster@yahoo.com.br

Mestrando no programa de Pós-graduação em Ciências Sociais na Universidade Estadual de

Maringá. Graduado em Ciências Sociais pela Universidade Estadual de Maringá (UEM), e em Comunicação Social, com habilitação em Publicidade e Propaganda, pelo Centro Universitário de Maringá (CESUMAR). Realiza pesquisas nas áreas de Análise do Discurso, Teorias da Comunicação e Pensamento Social Brasileiro.

\section{Resumo}

Explorando possibilidades de interpretação da obra do sociólogo Gilberto Freyre (1900-1987) e do comunicólogo Luiz Beltrão de Andrade e Lima (1918-1986) e inspirados pelos princípios da sociologia da ciência, pretendemos indicar pontos em que a obra e o pensamento dos dois autores se aproximam e/ou se distanciam

Palavras-Chave: Luiz Beltrão; Gilberto Freyre; Sociologia da ciência.

\section{Abstract}

Exploring possibilities of the work os sociologist Gilberto Freyre (1900-1987) and communicologist Luiz Beltrão de Andrade e Lima (1918-1986) and inspired by the principles of the sociology of science, we intend to indicate points at which the work and thought approach of the two authors is closer or more distant.

Keywords: Luiz Beltrão; Gilberto Freyre; Sociology of science. 


\section{Entre saberes: abordando práticas de relacionamento}

Atentos em entender as práticas intelectuais e científicas que caracterizam o relacionamento entre diferentes áreas do saber, buscamos explicitar pontos de interlocução entre autores clássicos das ciências sociais e do pensamento comunicacional brasileiro. Tentando elaborar novas possibilidades de interpretação e compreensão da memória histórica acerca das dinâmicas de relacionamento entre diferentes áreas do conhecimento, pretendemos mapear algumas possíveis proximidades ou distanciamentos entre o pensamento de Gilberto Freyre, principalmente a partir da obra "Sobrados e Mucambos" (1998), e o de Luiz Beltrão de Andrade e Lima, aqui representado pelo livro "Folkcomunicação: um estudo dos agentes e dos meios populares de informação de fatos e expressão de ideias” (2001).

Gilberto Freyre é um dos mais prestigiados sociólogos brasileiros e, como aponta Meucci (2006), exerceu um papel extremamente relevante para a consolidação da sociologia como disciplina científica no Brasil. Luiz Beltrão, por sua vez, foi o responsável por formular uma teoria sobre os sistemas comunicativos próprios à realidade brasileira e contribuiu para a profissionalização e institucionalização do jornalismo no País.

Ocupando posiçóes institucionais e científicas distintas, esses intelectuais possuem em comum um mesmo horizonte de problemas, a saber: a questão da integração nacional brasileira. No período imperial o debate girava em torno da garantia da unidade territorial diante de sucessivos conflitos e revoltas. Com o advento da República e o início do século XX, a integração social, econômica, cultural e política tornaram-se os principais temas tratados.

Por isso, um dos temas privilegiados na análise diz respeito, justamente, à integração nacional brasileira. Eixo em torno do qual nossos critérios explicativos se articulam. O debate acerca desse tema está presente na obra dos dois pesquisadores, permitindo que possamos elucidar o modo como cada um deles elaboram argumentos entorno dessa questáo e como tais argumentos se interligam ou se dispersam.

Em "Sobrados e Mucambos" (1998), Freyre constrói um retrato dos processos e dinâmicas que caracterizaram a integração nacional brasileira num contexto de urbanizaçáo incipiente, próprio da passagem do século XIX ao XX. Luiz Beltrão, em sua tese de doutorado, debate o tema a partir das suas especificidades na primeira metade do século XX, com a consolidação da ordem urbana.

Metodologicamente nos orientamos pelas elaborações da sociologia da ciência e nos apoiamos principalmente na ideia de Orlandi, quando afirma que não existe ideia fora do lugar, pois "as ideias não tem um lugar, têm muitos" (1993, p.7). Embora não seja central, o questionamento a respeito dos muitos lugares que uma ideia pode ocupar em diferentes contextos do saber, como esses lugares são intelectualmente formulados, quais os critérios que permitem a produção de um sentido de diferenciação ou de inter-relacionamento entre determinados entendimentos, busca ser presente na nossa reflexão. 


\section{Integração social e heterogeneidade cultural}

O debate sobre a integração nacional brasileira possui características singulares em cada uma das obras aqui analisadas. Produzidas em períodos históricos e contextuais distintos, essas obras se inscrevem em trajetórias intelectuais particulares. Freyre contribuiu para a sistematização do saber sociológico no país, dando os primeiros passos no sentido do fortalecimento institucional dessa ciência (MEUCCI, 2006). Beltrão escreve seu livro como requisito para obtenção do título de doutor em comunicação, demonstrando que na década de 1960 o saber comunicacional já gozava de reconhecimento científico e acadêmico no País, em parte, fruto do seu próprio empenho (MELLO, 2001).

Ambos os autores exerceram importante papel para o desenvolvimento das suas referidas áreas. A obra freyriana é responsável pela inauguração de algumas perspectivas que, em certos períodos, exerceram hegemonia nas ciências sociais brasileiras. Luiz Beltrão formulou a primeira teoria da comunicação genuinamente brasileira, auxiliou na organização dos primeiros currículos dos cursos superiores de comunicação no País, criou o primeiro centro de estudo dedicado ao tema e a primeira revista científica sobre o assunto.

Em Luiz Beltrão, a discussão sobre a integração nacional brasileira contextualiza suas reflexóes acerca das características dos sistemas comunicacionais do País. A heterogeneidade cultural é entendida pelo autor, como elemento produtor de distanciamentos e separaçóes (2001, p.53). Manifestando uma inclinação científica funcionalista; própria das teorias comunicacionais desse período que estão fortemente influenciadas pela sociologia norte-americana a partir da figura de Robert King Merton; Beltrão valoriza a homogeneidade, a unidade e a coesão. Embora o comunicólogo afirme que a existência de uma unidade mental, de um conjunto de ideias comuns a todos os habitantes do país, ele não nega a presença de distintos estágios de desenvolvimento social e econômico entre nós (Ibid., p.59). Tal diferença contribui para a construção de barreiras à integração nacional. Posto que, cada estágio de desenvolvimento possui uma prática comunicativa própria, adequada aos seus contextos intelectuais e políticos, dificultando a existência de um entendimento entre sujeitos que estão em estágios de desenvolvimento distintos.

Esses diferentes estágios são um dos responsáveis pelo desenvolvimento de uma dicotomia ético-cultural. De um lado, elites intelectuais e dirigentes, letrada e desenvolvida que se informa a partir dos modernos meios de comunicação massiva, o rádio, o jornal, a televisão; que habita o litoral, as regióes mais desenvolvidas, os grandes centros urbanos; de outro, classes populares e marginalizadas, analfabeta ou semianalfabeta, que não possui acesso aos meios massivos, que vive nas periferias, nos sertóes, no mundo rural; que se informa a partir da crença em seus catimbós. Segundo o pensador, essa dicotomia "desperta as nossas lideranças para o problema da comunicaçáo, como ponto de partida da nossa caminhada para o progresso" (BELTRÃO, 2001, p.64), tornando manifesto seu engajamento dentro de um determinado projeto político. 
Uma das ideias defendidas por Beltrão é a do necessário conhecimento da capacidade comunicativa das práticas populares e folclóricas, como maneira de promover a integração nacional e o desenvolvimento do País. Essa ideia se formula a partir de um determinado diagnóstico acerca da realidade social brasileira:

A realidade brasileira era constatada por sociólogos, psicólogos sociais, antropologistas,
politicos e economistas: dois brasis se defrontavam. Um em franco desenvolvimento
cultural e econômico; outro, marginalizado, entravando os planos do progresso. Um
respondendo com maior ou menor desenvoltura aos apelos dos meios de comunicaçáo
coletiva; outro náo suscetivel dessa influência e, por conseguinte, alienado dos objetivos
pretendidos pela elite. Um acreditando nas metas desenvolvimentistas e mudando os
seus padróes de comportamento ao influxo das ideias e das técnicas novas, difundidas
sobretudo pelos veículos jornalisticos; outro crendo apenas nos seus 'catimbós' e
rejeitando até mesmo uma argumentaçáo lógica, fundamentada em causas e efeitos
para aferrar-se aos seus preconceitos, hábitos e costumes tradicionais, e permanecendo
surdo às mensagens jornalisticas convencionais. (Ibid., p.74)

A heterogeneidade cultural, que gera distinçôes e diferenciação, é responsável pela produção da desagregação. Os diferentes atores sociais que compóem o cenário nacional, não gozam de uma unidade ético-cultural, pois não compartilham de um mesmo conjunto de valores, nem de um mesmo objetivo social. Para que a modernidade, entendida por Beltrão a partir da perspectiva desenvolvimentista da metade do séc. XX, fosse efetiva em todo o conjunto da nação seria necessário um movimento de integraçáo cultural e valorativa que criasse um objetivo comum para todas as esferas da população. A falta desse objetivo em comum leva o autor a entender que os valores modernos foram responsáveis, em grande parte, pela produção dessa dicotomia. É dessa forma que a heterogeneidade cultural, ao produzir diversificação social, gera desigualdades estruturais que impedem a existência de uma unidade cultural nacional.

Em Gilberto Freyre a questão da heterogeneidade cultural é elaborada de outra forma. Para o sociólogo (2006), a diversidade social brasileira é o que melhor caracteriza a nação. Uma nação envolvida em grandes conflitos valorativos, mas que cria formas e espaços de convívio capazes de amenizar os embates. No entanto, ao estudar a sociedade brasileira do séc. XVIII e XIX (FREYRE, 1998), o autor constata a existência de processos que contribuem para a extinção desses espaços e a consequente exacerbação dos conflitos.

As influências inglesa e francesa às quais o Brasil esteve fortemente submetido durante o período imperial produziu novas condiçóes de convivência que contribuíram para a desintegração da ordem patriarcal e o consequente enfraquecimento do patriarcalismo enquanto sistema organizador da esfera política e cultural. O velho patriarcalismo rural se adapta, ainda que com tensóes, ao novo cenário semiurbano e burguês. Nesse contexto, Freyre (1998) localiza a heterogeneidade cultural brasileira dentro de uma arena de conflitos entre valores distintos e opostos.

Opondo os valores orientais aos ocidentais, o pai ao filho, o patriarca ao bacharel, o espaço da casa ao da rua, o mundo urbano ao rural, o moderno ao atrasado; o movimento de reeuropeização que Freyre (1998) descreve, cria dicotomias e instaura novos modos de agir e de se 
comportar que posicionam os sujeitos em locais diferentes na hierarquia social, estabelecendo formas de sociabilidade que separam e segregam os indivíduos, criando barreiras para a integração dos diferentes grupos que compunham a sociedade de então.

O sobrado representa o espaço da nova ordem, da boa educação, da boa cozinha, do português adequado; no mocambo, a população negra e mulata marginalizada seguia reproduzindo valores desprezados pela nova ordem. Afirma Freyre: "o que se verificava repita-se era vasta tentativa de opressão das culturas náo-europeias pela europeia, dos valores rurais pelos urbanos (...)" (1998, p. 389), historicamente esse período se caracteriza pela existência de complexos conflitos sociais.

Não podemos afirmar categoricamente que a desintegração vivenciada nesse período é plena: primeiro porque esse processo ocorria dentro de uma arena de conflitos sociais e políticos; segundo, pois os primeiros ares da modernidade não fez só criar segregaçóes, mas permitiu também o fortalecimento de laços internos entre determinados grupos. Como demonstra Freyre, diferentes atores sociais se organizaram em torno da defesa dos seus valores e das suas crenças, chegando mesmo a institucionalizarem-se em confrarias, irmandades e corporaçóes de ofício (1998, p. 374). No entanto, esses movimentos expressam a existência de um conflito aberto entre valores distintos. $\mathrm{Na}$ sociedade brasileira do século XIX, não há mais zonas ou espaços de confraternização em que o conflito possa assumir uma realidade mais amena.

O processo de reeuropeização que Freyre (1998) descreve cria distâncias e instaura barreiras que vão dar origem a metades efetivamente conflitantes - $\mathrm{o}$ sobrado e o mocambo. Como afirma Araújo, ao discutir a obra de Freyre, "os mocambos dão a impressão de constituir uma cultura inteiramente separada" (1994, p. 134). A dicotomia entre esses espaços expressa diferenças culturais, econômicas e de sociabilidade que contribuem para a produção de uma ordem segregacionista e excludente, na qual cada espaço se desenvolve a partir da crença em valores específicos que se opóem um ao outro.

Freyre (1998) posiciona-se de maneira a compreender que a heterogeneidade cultural, dependendo da forma como é agenciada e articulada no universo social, pode explicitar a existência de conflitos valorativos que tendem a corporificar processos de desintegração e segregaçóes. Para o autor, a dicotomia entre diferentes espaços sociais pode caracterizar a existência de um conflito constitutivo da própria sociedade, sem o qual ela não poderia ser o que é.

Luiz Beltrão (2001) elabora um diagnóstico semelhante a respeito dessa questáo. Para o comunicólogo a heterogeneidade cultural pode gerar desintegração e desagregação, dificultando o processo de criação de uma unidade nacional. $\mathrm{O}$ autor argumenta que a dicotomia entre elite e povo, cada qual com práticas culturais e sociais específicas, contribui para a existência de uma sociedade sem unidade, destituída de uma harmonia capaz de lhe fornecer uma direção comum de desenvolvimento. 
Enquanto Beltrão (2001) se preocupa mais com as consequências políticas e econômicas da falta de unidade; Freyre (1998) está atento para entender processos históricos que produzem uma sociedade organizada em torno do estabelecimento de hegemonias potencialmente excludentes, que instauram práticas segregacionistas, dificultando o possível convívio harmônico e a integração entre sujeitos que possuem códigos culturais e valorativos distintos.

No que diz respeito à heterogeneidade cultural enquanto elemento importante para pensar a questão da integração nacional, é possível explicitar a existência de proximidades entre os dois autores. Tal proximidade não apaga diferenças argumentativas significantes. Os autores possuem pontos de partida diferentes, mas terminam encontrando-se em destinos semelhantes. Ambos terminam por atestar a existência de uma sociedade dividida entre grupos dominantes que possuem valores modernos e população marginalizada que fica excluída por não compartilhar desses valores.

Esse apontamento encontra justificativa na afirmação que Beltrão faz a respeito da fragmentação nacional:

Essa fragmentaçáo prosseguiria por todo o século IV e teria o seu ciclo completado com a abolição da escravatura, que retiraria à influência da casa-grande a significativa população da senzala. Os negros forros iriam engrossar a camada social dos alienados do pensamento e da cultura da elite. E incorporariam vigorosamente ao patrimônio sociocultural da favela, do mocambo e da tapera as suas tradicionais formas de expressão. Que o sobrado, o palacete e a casa-de-fazenda não compreenderiam, agravando-se a cada passo o abismo hoje constatado (BELTRÃO, 2001, p.77) $)^{8}$

Embora Beltrão não cite explicitamente a obra de Gilberto, é perceptível uma apropriação do pensamento freyriano pelo autor.

Outro argumento elaborado por Beltrão é de que a desintegração é causada, em partes, pela inexistência de práticas comunicativas eficazes e adequadas a nossa realidade. Reinterpretando nossa história, o autor afirma que as práticas comunicativas primitivas dos indígenas foram essenciais durante a colonização para assegurar a unidade a esses grupos (Ibid., p.83). O branco colonizador necessitou primeiramente aprender o idioma nativo para depois forçar a população nativa a abandonar sua língua. Afirma o comunicólogo que:

através de um exame sistemático das relaçôes entre os indígenas e os brancos (franceses e holandeses, entre os estrangeiros; jesuitas e portugueses, entre os colonizadores) pretendemos fixar a subordinação do nosso desenvolvimento cultural, social e econômico à existência de um entendimento entre os grupos heterogêneos da colônia, mesmo quando se combatiam e exterminavam, visando, consciente ou inconscientemente, a constituição de uma sociedade espiritualmente autônoma, homogênea e progressista. (Ibid., p.95)

Esse entendimento se fazia a partir da existência de uma língua comum. Segundo Beltrão (2001), a estratégia de aprender a língua nativa foi essencial para o sucesso da catequização do indígena promovida pelos jesuítas. Ao criar condições para a interação entre sistemas simbólicos distintos, os padres da 
companhia conseguiram promover uma unidade de pensamento entre a população nativa e os colonizadores que, na perspectiva beltraniana permitiu a consolidação da nossa independência sem vozes discordantes (Ibid., p.122). Compreensão semelhante é elaborada por Freyre (1998; 2006), quando discute a presença e a importância do jesuíta para a formação da família brasileira.

Levantamos a questão da língua, pois ela está atravessada por variáveis importantes para a análise. A referida heterogeneidade cultural que debatemos até aqui não existe apenas no plano abstrato dos valores, mas se materializa nas práticas dos atores sociais. Das obras analisadas, um ator social que aparece em ambas, é o padre jesuíta. Assim, discutiremos como se formula em cada autor a relação entre atores sociais e práticas culturais específicas que explicitam a nossa heterogeneidade cultural, e como isso influencia a produção de uma integração nacional.

Em Beltrão, os jesuítas foram responsáveis por criar a unidade necessária para a realizaçáo da independência e por consolidar uma rede de comunicação que ligava os pontos distantes do País a partir das suas reduçóes (BELTÃO, 2001, p.97). Os missionários exerceram importante papel na configuração da nossa sociedade nascente. Como afirma o autor, os padres da companhia deixaram como legado:

(...) a integração do silvicola na sociedade brasileira, a sua participação no todo nacional, o estabelecimento de relaçôes vivas e atuantes entre os dois grandes blocos raciais que, embora operando em áreas sociais diversas, se entendiam e completavam, miscigenavam-se por assim dizer, para a obtenção daquela unidade de pensamento e ação que resultou na independência (Ibid., p.117).

O jesuíta, a partir das suas técnicas comunicativas e educacionais, conseguiu criar na colônia um ambiente favorável à admissão de novas ideias e valores que orientariam o comportamento daqueles que estavam submetidos a sua influência. Ela era sentida especialmente pelos atores mais frágeis dessa sociedade. No seu afã de catequisar o selvagem, o jesuíta investia suas forças na educação da criança, do curumim. Era a partir dele que o padre realizava o seu trabalho de conversão dos adultos. O curumim fazia a ligaçáo entre os valores tradicionais da sua sociedade nativa e os novos valores ocidentais católicos importados pelos jesuítas, ele faz a mediação necessária para a consolidação de uma nova ordem. A estratégia que melhor se adequou aos objetivos jesuíticos foi, de fato, o domínio do idioma nativo para conquistar a confiança dessa população e, posteriormente, a conversão do nativo ao idioma estrangeiro, fortalecendo os processos de dominação e de alteração da ordenação social.

Freyre (1998), no capítulo intitulado "O Pai e o Filho", mostra que os colégios jesuítas foram os responsáveis por educar a geração dos bacharéis republicanos e abolicionistas, que contestaram a velha ordem patriarcal e se insurgiram contra o tradicionalismo do mundo rural, assumindo os valores ocidentais europeus como modelo de desenvolvimento social. É no colégio 
jesuíta que o filho do patriarca entra em contato com esse novo conjunto de valores, essa mudança se expressa especialmente no domínio da língua. É sob a influência jesuítica que a criança perde os velhos vícios de linguagem da casa grande e aprende o português mais adequado para a nova ordem, limpo da influência africana e moura. Novamente é a criança o depositário da confiança dos padres no seu empreendimento educador. Também em "Casa Grande \& Senzala”, Freyre (2006) debate a importância do padre capeláo para formação de indivíduos adequados à ordem social.

Essa geração educada pelos padres terá no português culto um dos seus principais elementos de distinção em relação aos outros membros da sociedade, e um importante signo de auto reconhecimento, fortalecendo laços de pertencimento grupal. Essa dinâmica permite entender que as lutas políticas também se expressam em espaços simbólicos, que há sempre práticas materiais tornando visíveis conflitos ideológicos e valorativos.

O jesuíta e o padre capelão como ator social, em ambas as obras aqui analisadas, atuou como produtor de integração e desintegração. Ao ensinar novos valores e novas práticas, os padres preparavam o terreno para a construção de uma nova ordem social, gerando integração entre aqueles escolhidos para fazer parte dessa nova ordem. No entanto, essa tarefa resultou também na desintegração de ordenaçôes tradicionais e mais do que isso, na produção de uma nova ordem quase sempre excludente, na qual aqueles que não assumissem os novos valores sociais veriam reduzidas as possibilidades de interação e participação social.

Com suas práticas educativas, os jesuítas foram responsáveis pela inserção de novos valores na sociedade brasileira, valores que possibilitaram o rompimento com antigas tradições e a construção de novas configuraçóes sociais. Em Freyre (1998), o jesuíta é responsável por educar a geração que construirá a república, a ordem urbana e burguesa. Em Beltrão (2001), os padres constroem o sentimento de unidade que culmina com a independência. Cada autor possui especificidade que cremos ter esclarecido. No entanto, ambos se aproximam em suas interpretaçóes sobre a presença e ação dos jesuítas no Brasil.

Seguindo a pista dos atores sociais e das práticas coletivas capazes de materializar nossa heterogeneidade cultural, e a influência disso na produção da integração nacional, destacamos agora a figura do mascate.

Freyre faz uma breve referência a esse sujeito (1998, p. 34). Presente no espaço da casa-grande e do sobrado, o mascate circulava livremente nesses lugares. Trazia para o interior da família tradicional as últimas modas e demais produtos, quebrava a rotina cotidiana desses ambientes "levando para o interior desses quase-conventos um pouco do ruído da rua e das novidades da praça” (Ibid., p.36). Ou seja, realizava uma função diversificadora, contribuindo para a inserçáo de novos produtos, valores, modelos de convivência e comportamentos no espaço familiar da casa, que no século XIX, opunha-se a rua e seus perigos. 
O mascate exerce uma função semelhante na compreensão de Luiz Beltrão. Durante o século XIX, juntamente com os jesuítas e outros atores sociais, ele agrega forças na produção da unidade que permitirá a independência. Atualizado na figura do caixeiro viajante do século XX, é ele quem vai viabilizar a integraçáo comercial entre sertão e litoral, mais do que isso, por ter acesso livre em diferentes espaços sociais, por circular entre diferentes extratos da nação, esse ator possui uma capacidade de agir como mediador comunicacional entre os dois brasis, aproximando pontos cultural e geograficamente opostos.

É especialmente nesse leva-e-traz de informaçóes, nessa troca de impressóes e opinióes, nesses amistosos (e interesseiros) debates, na imensa quantidade de anedotas e xistosos ditos com que salpica a sua parolagem negocista, que está a sua mais viva contribuição à divulgação de fatos e ideias. 'Ninguém é capaz de avaliar o seu esforço em benefício do desenvolvimento do nosso país. Se esta pobre civilização brasileira saiu do litoral e veio até aqui (o sertão) foi carregada nas nossas costas' - comenta um deles. (BELTRÃO, 2001, P.147).

Mais uma vez, Gilberto Freyre e Luiz Beltrão demonstram proximidades argumentativas e de entendimento acerca da realidade social brasileira. Ambos percebem na figura do mascate um agente de diversificação e integração social, promovendo a interação entre diferentes conjuntos de ideias e valores, gerando unidade, ao estabelecer relacionamento entre espaços sociais distintos e opostos. Para ambos os autores, tanto o jesuíta quanto o mascate se constituem como mediadores dos processos de integração ou segregaçáo.

A partir desse debate, podemos afirmar que a questão da integração nacional nas obras analisadas perpassa e é perpassada pelo tema da heterogeneidade cultural de atores sociais que materializam essa heterogeneidade e de estratégias políticas e práticas coletivas empregadas para a produção de integração ou desintegração social.

Os critérios analíticos que levantamos até agora, possuem um peso mais teórico do que prático ou metodológico, no sentido de que tentam localizar intelectualmente o espaço conceitual no qual as referidas obras se inserem. Não poderíamos esquecer-nos de, ainda que brevemente, apontar características de ordem metodológica e técnica que nos auxiliam a compreender o caráter do relacionamento entre o saber comunicacional e o saber social a partir das obras estudadas. Procedimentos de pesquisa utilizados, fontes de estudo privilegiadas e técnicas analíticas empregadas, são elementos que nos dispomos a compreender.

A vasta referência que Freyre (1998) faz aos jornais da época não deixa dúvidas sobre a sua maior inclinação à pesquisa em fontes ortodoxas, que garantem mais legitimidade e reconhecimento, além de ilustrar com mais precisão as afirmaçôes e os argumentos que o autor elabora. Contudo, fontes menos ortodoxas também estáo presentes na obra do sociólogo, sobretudo aquelas que não possuem um registro escrito e que se encontram dispersas no espaço social. 
É o caso dos modos de falar, das formas de agir e se vestir, das técnicas corporais, da culinária, dos temperos, do jardim, dos hábitos de lazer, são várias as práticas culturais que Freyre analisa tendo como fonte a vida cotidiana da sociedade brasileira. Essa habilidade em equacionar a contribuição de diferentes fontes, permite que o autor chegue a utilizar representaçôes folclóricas como material de análise para validar sua argumentação.

Ao discutir a questáo da miscigenação no Brasil patriarcal e semipatriarcal, no último capítulo da sua obra, o autor recorre às cantigas e versos folclóricos como maneira de ilustrar o preconceito e o desprezo que o mulato sofria naquele contexto (Ibid., p. 632). Amparado pelo trabalho de folcloristas como Alfredo Brandão e Rodrigues de Carvalho, Freyre utiliza a fonte folclórica para entender o pensamento daqueles extratos da população que não possuíam acesso aos meios de comunicação ortodoxos, que se utilizavam da oralidade para exprimir suas ideias e opinióes.

Como a proposta metodológica encabeçada por Beltrão (2001) é justamente essa, a de compreender o folclore a partir da sua capacidade comunicativa. Será embasado em material recolhido por folcloristas que Beltrão irá desenvolver seus argumentos. O comunicólogo traz vastos exemplos de cantigas populares, versos, poesias, literatura de cordel, almanaques, folhetos, entre outros, que possuem a capacidade de materializar os valores, a moral e o pensamento próprio das populaçôes menos favorecidas.

No que diz respeito à abordagem analítica, podemos afirmar que a obra de Freyre (1998) possui um caráter mais histórico-político. Buscando entender dinâmicas históricas da nossa cultura, Freyre não possui o objetivo manifesto de fazer da sua obra subsídio para ação política direta, embora ela tenha sido apropriada a partir dessa perspectiva. As análises que o autor elabora possuem uma tendência a perceber o conflito como ponto nodal das relaçôes sociais, é nesse sentido que em Freyre o conflito é constitutivo da realidade, algo que diz respeito ao próprio caráter do que é o convívio em sociedade. Para o sociólogo, a existência do conflito não apaga a possibilidade de uma convivência harmônica, daí a necessidade de observar como os processes de integração ou segregação social e cultural se elaboram num cenário de conflitos perenes.

Já a análise de Beltrão (2001) pode ser caracterizada como político-histórica, pois pretende se transformar num mecanismo de mobilização e transformação política e social. A todo o momento o autor afirma o necessário conhecimento das práticas folkcomunicativas com o intuito de melhorar a integração entre os diferentes grupos da nação, facilitando a implementação dos planos e metas desenvolvimentistas e a consequente transformação da realidade social das populaçóes menos favorecidas. No pensamento do autor, o conflito surge como algo a ser superado, a ser substituído pelo alcance de uma ordenação harmônica e coesa, onde toda a nação possua um mesmo objetivo social, político e econômico. 
Mesmo com enfoques analíticos distintos e posicionados em espaços institucionais diferentes, cada qual com coordenadas teóricas particulares, ambos os autores aqui analisados chegam a conclusôes semelhantes em diversos pontos. Como esperamos ter demonstrado, a dinâmica de relacionamento entre o saber comunicacional e o saber social no Brasil se caracteriza pela existência de uma conexão possível graças a presença de um horizonte de problemas comuns e a produção de diagnósticos semelhantes a respeito da realidade social brasileira.

Como plano de fundo que embasa diferentes reflexôes, a conceituação sobre as características do Brasil nação conecta o pensamento social ao pensamento comunicacional no momento em que permite a integração de diferentes enfoques e temáticas em torno de uma mesma questão. Diferentes são os argumentos e a maneira como cada autor articula esses argumentos com seus temas analíticos privilegiados, diferente também são as posiçôes institucionais a partir da qual cada autor enuncia, no entanto, Gilberto Freyre e Luiz Beltrão acabam por se localizar dentro de um mesmo contexto discursivo.

\section{Caminhos abertos: o que ainda há por descobrir}

Como forma de corroborar o argumento que aqui defendemos, de que existe forte proximidade entre o pensamento social de Gilberto Freyre (1998) e o pensamento comunicacional de Luiz Beltrão (2001), no que diz respeito à maneira como cada autor compreende a questão da integração nacional brasileira e o diagnóstico que elaboram sobre a nossa realidade social; recortamos duas citaçôes conclusivas da obra de cada um dos autores que ilustram nossas ideias.

Ao findar sua obra Freyre afirma:

Mesmo, porém, a essa fase de maior diferenciação social entre sobrados e
mucambos, correspondentes à maior desintegração do sistema patriarcal entre nós,
náo têm faltado elementos ou meios de intercomunicaçáo entre os extremos sociais
ou de cultura. De modo que os antagonismos que não foram nunca absolutos, não
se tornaram absolutos depois daquela desintegração. E um dos elementos mais
poderosos de intercomunicação, pelo seu dinamismo de raça, e principalmente, de
cultura, tem sido, nessa fase difícil, o mulato (1998, p. 659).

Enquanto Beltrão, na conclusão do seu livro afirma que:

Os dois brasis - o do litoral e dos centros altamente industrializados, com suas populaçóes sujeitas à influência da imprensa, do rádio, da televisão e do cinema e com maiores facilidades de elevação do seu nivel cultural; e o hinterlândia, mergulhado num quase isolacionismo e falta de condiçôes e predisposiçóes para aceitar novas ideias e efetuar uma mudança social a curto prazo, como reclama o ritmo do progresso cultural e tecnológico da humanidade - os dois brasis diferem profundamente em graus de cultura e economia, em linguagens, em meios de expressão. Contudo, identificam-se por suas origens étnicas, seus ideais filosóficos e politicos, seus espiritualismos e pelo idioma comum, o que lhes facilita um entendimento, vez que as elites culturais e dirigentes saibam usar os instrumentos e as técnicas adequadas a uma comunicação positiva e eficaz (2001, p. 256) 
Atestando a existência de uma dicotomia que dividia a nação em dois grandes grupos, ambos os autores se preocupam com as consequências sociais e políticas dessa falta de integração social. Não compartilham de um mesmo objetivo, pois possuem projetos intelectuais e políticos distintos, cada qual com suas temáticas e práticas características. No entanto, aproximam-se no que diz respeito à forma como produzem uma determinada interpretação sobre a realidade social brasileira.

Ao estruturar nossa análise a partir do eixo central da integração social brasileira, criando critérios explicativos e comparativos como heterogeneidade cultural, atores que expressam essa heterogeneidade e práticas sociais que materializam a diversificação social, buscávamos explicitar as dinâmicas que poderiam caracterizar o relacionamento entre pensamento social e pensamento comunicacional brasileiro. Sabemos agora que essa relação existe, que é possível mapeá-la, produzindo uma pequena cartografia sobre os processos de interação intelectual entre essas áreas do conhecimento. Sabemos também que há um trabalho substancial a ser realizado na direção de verificar o grau, a intensidade e as consequências intelectuais e institucionais desse relacionamento, tendo sempre em vista a preocupação em tornar visível os processos e as práticas nas quais ele se sustenta.

\section{Referências Bibliográficas}

ARAÚJO, Ricardo Benzaquen de. Guerra e Paz: Casa-Grande \& Senzala e a obra de Gilberto Freyre nos anos 30. Rio de Janeiro: Editora 34, 1994.

BELTRÃO, Luiz. Folkcomunicação: um estudo dos agentes e dos meios populares de informação de fatos e expressão de ideias. Porto Alegre: EDIPUCRS, 2001.

FREYRE, Gilberto. Casa - grande e Senzala: formaçâo da família brasileira sob o regime da economia patriarcal. 51ª ed. São Paulo: Global, 2006.

. Sobrados e Mucambos: introdução à história patriarcal no Brasil - 2. 10. ed. Rio de Janeiro: Record, 1998.

MELLO, José Marques de. (Org.). Mídia e Folclore: o estudo da folkcomunicação segundo Luiz Beltrão. Maringá/São Bernardo do Campo: Faculdades Maringá /Universidade Metodista de São Paulo / Cátedra Unesco de Comunicação, 2001.

MEUCCI, Simone. Gilberto Freyre e a Sociologia no Brasil: da sistematização à constituição do campo científico. Tese (Doutorado em Sociologia)Instituto de Filosofia e Ciências Humanas, UNICAMP, Campinas, 2006.

ORLANDI, Eni. (Org.) Discurso fundador - a formação do país e a construção da identidade nacional. Campinas: Pontes, 1993.

ORTIZ, Renato. Cultura brasileira e Identidade Nacional. São Paulo: Brasiliense, 2006. 